Accepted by Gender Work and Organizations journal 6 February 2018

In the steps of Joan Acker: A journey in researching inequality regimes and intersectional inequalities ID GWO-17-316.R1

Geraldine Healy, Ahu Tatli, Gulce Ipek, Mustafa Ozturk, Cathrine Seierstad and Tessa Wright

Contact: g.m.healy@qmul.ac.uk

Centre for Research in Equality and Diversity

School of Business and Management

Queen Mary University of London 


\title{
In the steps of Joan Acker: A journey in researching inequality regimes and intersectional inequalities
}

\begin{abstract}
Inspired by two of Acker's interconnected concepts, inequality regimes and intersectionality, the authors revisit their intersectional research. By exploring their various studies on inequality regimes and intersectionality, the authors propose some novel insights that have emerged from an aggregate appraisal of some 17 empirically researched papers, all shaped by Joan Acker's sociology. While Acker's work on gender and organizations has provided crucial insights into much of this work, this article concentrates on the overarching concept of inequality regimes and then focuses in on less-developed aspects of intersectionality in Acker's work. In doing so, it reconsiders the value of inequality regimes in pushing the boundaries of intersectional insights.
\end{abstract}

\section{Introduction}

This article focuses on the legacy of Joan Acker's influential and pioneering work in the academy. In particular, the article concentrates on the way the overarching concepts of inequality regimes have been used in employment and organizational research and then considers how less-developed intersectional aspects of inequality regimes in her work have been developed through later empirical studies. In theorising gendered organizations, Acker's (1990) key insight was that gendered beliefs and values enmeshed with institutional structures to create enduring systems of stratification along the gender axis. With some 6,000 citations, in her foundational work on gendered organizations, Acker theorized the unequal nature of organizations and argued that 'The positing of gender-neutral and disembodied organizational structures and work relations is part of the larger strategy of control in industrial capitalist 
societies, which, at least partly, are built upon a deeply embedded substructure of gender difference' (Acker, 1990, p. 139). Thus, gender is constructed as the difference that matters in who gets what types of jobs, for how much pay, and gender is also the signifier of an unequal symbolic allocation of recognition, power and status between men and women.

The revolutionary nature of this perspective is its eschewal of the reductive, individualistic understandings of women's work and employment experiences to pivot the explanation for gender inequality to the level of structure (Britton and Logan, 2008). In clearly drawing links between the structural and individual processes shaping gendered power relations and hierarchies, Acker (1990) was among the feminist writers who highlighted the body as a site of important gendered and sexualized processes (Adkins, 1995; Burrell and Hearn, 1989; Cockburn, 1991; Halford et al., 1997; McDowell, 1997; Wolkowitz, 2006). As well as being a formidable theorist revealing the gendered nature of apparently neutral everyday organizational practices, Acker sought to link the work of practical feminist action with the work of feminist theorizing (see Acker, 1989, p.vii).

Joan Acker's earlier work (1990) on the "gendered processes" operating within organizations has been hugely influential in understanding how gender disadvantage is created and sustained in the workplace, pinpointing its operation at multiple levels, covering the labour market and other social structures, symbols, personal interactions and identities. Nevertheless, she was aware that the different lives of women and men could not be fully understood without understanding class and race differences in any gender analysis (ibid, p. 14), and later went further by moving beyond gender regimes to take account of 'inequality' regimes (Acker, 2006a,b). Thus, she sought to build on her earlier arguments about the gendering of organizations by reconceptualising her analytical framework to include class and race (2006b, p. 443). The inequality regimes framework recognizes the salience, and necessity, of an 
intersectional approach to inequality at work, by incorporating key insights from the intersectionality literature, which argued that non-white, non-middle-class women's lives were often badly neglected in both theory and practice, rendering entire groups of actors epiphenomenal (see, for example, Crenshaw (1991) Collins (2000), hooks (2000) and McCall 2005). Acker (2006b) also believed that understanding the previously unexamined or silenced work lives requires strong sensitivity to multiple and simultaneous intersectional advantages and disadvantages experienced by the full range of workers in the organsational context.

Acker viewed inequality in organizations as systematic disparities between participants in power and control over goals, resources and outcomes; workplace decisions; opportunities for promotion and interesting work; security in employment and benefits; pay and other monetary rewards; respect; and pleasures in work and work relations (2006b, p. 443). For Acker, all organizations have inequality regimes, which she defined as "loosely interrelated practices, processes, actions, and meanings that result in and maintain class, gender and racial inequalities within particular organizations" (Acker, 2006b. p. 443). With this conceptualization, Acker $(1990,2006 a, b)$ did not only put the organization at the centre of the sociological analysis, and but at the same time contested psychological or economic approaches that justify unequal outcomes as a direct transposition of divergent individual endowments and/or traits rather than as symptoms of structural inequalities. Thus, while inequality regimes are highly various, fluid and changing, Acker's framework always maintains a strong sociological link between organizational inequalities and inequalities which exist in the surrounding society, its politics, history and culture.

Acker's work has been a major inspiration in the work we carry out in the Centre for Research in Equality and Diversity (CRED) at Queen Mary University of London, since its inception in $2005^{\mathrm{i}}$ and which today has some 20 academics from a range of disciplines and 23 
PhD researchers. In 2007, Joan Acker delivered the first CRED annual lecture: 'Organising in search of diversity and equality: Whose ends, what means?' Many of us still remember our lively discussion with Joan on change and inequalities, what works for whom and what does not. And over the years, Acker's work continued to offer us new critical lenses and analytical devices to research inequalities in organizations and their complex intersectionalities. Inspired by the sociological tools Acker offered, in CRED, our research has covered inequalities and diversities spanning across different national contexts, for example in the UK, USA, Norway, China, Pakistan, Bangladesh, Nigeria, the EU. It has also explored inequalities in public and private sector industries from construction, transportation and manufacturing to retail, higher education, finance, healthcare, the civil service, and arts and culture; and focused on different equality strands including sexual orientation, gender, ethnicity and race and social class. We have also used Acker's insights to bring inequalities into more mainstream theories, concepts and fields through critical work on, for example, sociological insights from Bourdieu, Layder, Mills, studies on work, individualism and collectivism, rationality and diversity management studies. Moreover, our doctoral researchers have found considerable value and traction in Acker's work and we have formalized this by including Acker's work in our PhD training. Her work lends itself well to enabling $\mathrm{PhD}$ researchers to handle complex, multiple and mutually constituting concepts through a critical inequality lens and ensures that her work is passed on to the next generation of international scholars (including co-authors), such as Cynthia Forson, Gozde Inal, Gulce Ipek, Deborah Osei, Emily Pfefer, Cathrine Seierstad, Ahu Tatli, Tessa Wright to name a few.

In this paper six members of CRED, at different stages in our careers, revisit the journey we took with Acker, particularly inspired by two of her interconnected concepts, inequality regimes and intersectionality, and reflect on the novel insights our research 
generated owing to the analytical capacity Joan Acker's sociology has furnished us with. Acker's work on gender and organizations has provided crucial insights into so much of our work; but for this paper, we concentrate on the overarching concept of inequality regimes and then focus in on less-researched intersectional elements in her work and the value of inequality regimes in enabling intersectional insights. We have also gained many insights from key writers on intersectionality (e.g., Young, 1990; Crenshaw, 1991; Anthias, 1998; hooks, 2000; Brah and Phoenix, 2004; Hancock, 2007) who in different ways inform our interpretations of inequality regimes in particular contexts. We believe that our collective body of work has elaborated on Acker's concept of inequality regimes beyond the way it was originally articulated by Acker and in doing so we owe her a strong debt of gratitude.

\section{Inequality regimes}

In this section, we present our reflections on how and why we used the concept of inequality regimes and the importance of inequality regimes as a rich and imaginative framework to explore empirical topics. It has enabled us to discover new insights and in our own way to contribute to the development of 'inequality regimes' in practice.

Acker stated that she developed 'the concept of regimes of inequality as a way of understanding the dynamics of gendered racialized class relations within specific organizations' and she argued that regimes of inequality may also be useful in analysing complex stories of organizational conflict and change (Acker, 2006a, pp. 105-6). She saw organizations as central to class processes because capitalist economies function through organizations where practices are major constitutive elements of how class operates in communities, nations and across national boundaries. Acker views inequality regimes as a way 
to explore how organising practices are at the same time gendered and racialized class practices (2006a, p. 109). For Acker (2006b, p. 444-454) inequality regimes have six components: "the bases of inequality, the shape and degree of inequality, organizing processes that create and recreate inequalities, the invisibility of inequalities, the legitimacy of inequalities, and the controls and compliance that prevent protest against inequalities" and include some subcomponents. Acker drew her examples from her vast insight into the scholarly work of others; from early socialist feminist and Marxist feminist debates to the postcolonial feminist discourses of the beginning of the $21^{\text {st }}$ century, as well as her own research work on women returning to work, a comparable worth project in Oregon and a study of female bank workers in Oregon and Sweden (Acker, 1989). These studies and their empirical realities were important in informing what she called her 'sometimes abstract discussions' (2006b, p. 5).

For us, Acker's conceptual work on inequality regimes offered a powerful conceptual approach to make sense of our multiple empirical studies of organizations, and it is through these empirical studies that we are able to develop and critique the inequality regimes concept, and crucially, attest to its value. Acker has, of course set us a formidable challenge. To what extent do we need to take on board all six components when working to operationalize inequality regimes in empirical research or to focus on those most likely to illuminate our research questions? Is the concept without value if all six components are not included? Some of our work is informed by all six components, particularly in the context of race, gender and class, so that the framework of inequality regimes helps make sense of for example, a complex study of black and minority ethnic women's lives, their careers and their experiences as union members. Thus, an overview of inequality regimes provided the opportunity to explore the interrelationships of employer and union strategies in the context of women's actions of resistance and compliance in the light of their career and community actions and strategies 
(Bradley and Healy, 2008). On a practical level, this work benefited from being a monograph where the research could be developed more extensively.

However, Healy, Bradley and Forson (2011) observed that Acker appears to give equal "analytical weight" to all six components, but they argue that in different settings, some components may come to the fore, whereas others, reflecting a particular context, may merit 'lighter' treatment. These decisions might be intellectual or pragmatic. The discipline of writing for journal publication forces (often reluctantly) a level of selection as to which components might be included as part of the primary story while other components might remain part of the backstory. Our work evidences this selection process, for example, Healy, et al., (2011), Seierstad and Healy (2012), Tatli and Özbilgin (2012a), Tatli, Ozturk and Woo (2017) and Wright (2016a). We consider some of these 'choices' and their contributions.

Healy et al. (2011) focused on four of the inequality regime components, which are mutually constituted with the bases of inequalities and the shape and degree of inequalities, (a) the organizing processes that produce inequalities and its sub-components of workplace interactions and promotion practices, (b) the visibility of inequalities, in particular awareness of equality and diversity policies and awareness of inequalities and role models (c) the legitimacy of inequalities and their reproduction at different levels in the organization and (d) control and compliance, which is manifested in power derived from hierarchical gender and race relations and impedes changes in inequality regimes. This approach allowed the uncovering of the apparent paradox of the resilience of inequality regimes in public sector organizations explicitly committed to equality.

As stated above, Acker highlighted the informal interactions while 'doing the work' $(2006 \mathrm{a}, \mathrm{b})$ as one of the key organizing processes that produce inequalities in work organizations. Our work (e.g. Healy et al., 2011; Wright, 2011) acknowledged the importance of informal interactions. Healy et al. (2011) argued that the sub-component of informal 
workplace interactions is crucial in the reproduction of inequalities, often undermining the good intentions of formal practices, thus reflecting Acker's view that while public sector policies and practices are more open to examination and political pressures, they have much the same sorts of class-linked hierarchies and organising practices as private sector firms (Acker, 2006a, p. 107). Using evidence from gender-unequal workplaces, Wright (2011) highlighted the significance of informal processes, which frequently contradict formal policies and practices, in the reproduction of inequalities of gender, sexuality and occupational class. Wright (2011) further added that informal workplace interactions intertwine with the component of control and compliance in her treatment of workplace interactions between women and their male colleagues in male-dominated private sector environments. Sexual harassment is described by Acker variously as an aspect of informal interactions (2006b, p. 451) and an element of control and compliance (2006a, p. 123). Extending this to homophobic harassment, Wright (2011) suggests that one reinforces the other, as the intention of harassment is to control, while it is typically practised within informal interactions. The reluctance of those suffering harassment to complain for fear of being seen as a 'troublemaker' maintains the gap between formal policies and informal practice, and has a particular contemporary resonance in 2017. Informal interactions may thus be of greater significance in the daily experience of work than formal policy statements.

Acker's long-held concern with the relationship between gender, bodies and hierarchies (1990), was brought to the fore in Wright's work where women's sexual availability and orientation was a subject of great interest among men, together with presumptions about lesbian sexuality, when women enter 'male' work. Acker's understanding of how women's bodies are 'ruled out of order, or sexualized and objectified in work organizations' (Acker, 1990, p. 152) was crucial to Wright's (2016a) analysis of how both gender and sexuality interact to shape the experiences of female workers in the highly male-dominated environments of the 
construction and transport industries. Such interest can manifest itself in forms of 'humour', 'banter', and everyday sexualization in which the boundaries between sexualized interactions and sexual harassment are 'extremely fuzzy' (Halford et al., 1997, p. 256). Heterosexual women and lesbians can experience this sexualization differently, with open lesbian sexuality at times helping women workers avoid unwanted sexual attention, while on other occasions sexual minority status can be a further target for homophobic harassment (Wright, 2016b). Moreover, our cumulative research confirmed Acker's view that inequality regimes are variable between organizations. For example, Wright (2016a) found variability of sexualized environments occurred within different parts of organizations, with the work locations of nonprofessional women (such as building sites and bus garages) often operating as more overtly sexualized environments than the office environments of professional women.

Similarly, Tatli, Özturk, and Woo (2017) concur that certain components of inequality regimes might be given analytical prominence depending on the nature of the research question posed, which in their research was "where is the responsibility for achieving gender equality located in Chinese organizations?" This question requires our attention to the multi-level influences ranging from macro-societal to micro-individual. By specifically focusing on three components of inequality regimes (i.e. visibility, legitimacy, and control and compliance), Tatli et.al. (2017) were able to explore how the forces percolating in the wider economy and society help sustain organizational inequality regimes. They found that organizations abjure the responsibility for gender equality through the twin processes of marketization and individualization, which are reproduced by means of invisibility, legitimacy and control/compliance.

Another crossroads in adopting equality regimes in empirical research is reached when deciding on the unit of analysis. Acker developed the concept of inequality regimes for organizational analysis of inequalities in capitalist societies. In her doctoral research on 
gendering practices within three occupational groups in Norway, i.e. politics, academia and corporate boards, Seierstad (2011) expanded the explanatory power of inequality regimes into occupation and industry level analysis, reflecting Acker's wider concern that organizational processes and practices reflect the capitalist system. Norway and the other Scandinavian countries are characterized as having a social democratic welfare approach form of capitalism (Esping-Andersen, 2002). Moreover, on all international measures of gender equality Scandinavian countries emerge as more equal, with Norway as frequently identified as the most equal of countries, although superseded by Iceland in recent data (World Economic Forum 2017). Moreover, Norway has led the way in requiring the boards of public limited companies to have at least 40 per cent women as board members (Seierstad, Warner-Søderholm, Torchia and Huse, 2017). Thus, Norway is an example of Acker's view that under favourable circumstances, public sector policies and practices support affirmative action and pay equality (Acker, 2006a, p.107). Yet, despite a favourable public policy approach supporting gender equality, vertical and horizontal segregation remains resilient in Norway and the Scandinavian countries. Analysing the impact of affirmative action, Seierstad (2011) concludes that inequality regimes are buoyant in Norway, where despite international recognition, gender inequality is still more of an aspiration than reality at the organizational level. Seierstad's (2011) research has moved the "women on boards" research forward using Acker's theory as a sociological anchor to explain that progressive change requires multiple-level interventions because inequality regimes at organizational level are embedded in a wider macro regime of inequality.

Returning to the importance Acker accords to the historical, social and economic context in understanding organizational inequalities, Seierstad and Healy (2012) in their study of academics in Norway, Denmark and Sweden also show how inequality regimes conspire to limit women's aspirations or ensure that women pay a higher price for success than do men. 
They argue that deterministic accounts of the impact of the welfare model need to be tempered with insights into the reality of inequalities in organizations. They show that the interrelationship of the macro social and political context with the experiences at the organizational and occupational level reveals between and within country similarities and differences (Seierstad and Healy, 2012).

Similarly, in their study of employability and work placement in the UK arts and cultural sector in Britain, Tatli and Özbilgin (2012a) highlighted the relevance of the concept of inequality regimes beyond the organizational level. Drawing on interviews with students, employers and higher education institutions, the study particularly highlights the usefulness of two components of inequality regimes in sectoral analysis: the visibility and legitimacy of inequalities. Tatli and Özbilgin (2012a) hold that unlike the other components of inequality regimes that are more or less bounded by organizational practices, the legitimacy and visibility of inequalities form a bridge between organizational and the wider historical, political and economic context. In this context, the use of Acker's concept of inequality regimes beyond organizations allows us to attend the relationality between levels of inequality. Through the inclusion of legitimacy and visibility among the six components of inequality regimes, Acker bridges the organizational and societal level analysis.

Organizations and their practices and processes reflect wider societal influences including historical, political and economic, which found their expression in these last two components of inequality regimes.

A key finding which emerged from Tatli and Özbilgin's (2012a) research is that the variability of the visibility and legitimacy of inequalities is relative to the vantage point of the sectoral actors. As Acker (2006b, p. 452) succinctly put it, "visibility (of inequality) varies from the position of the beholder". Tatli and Özbilgin (2012a, b) called for a focus on privilege as a core research area, based on their research, which demonstrated that class and 
race inequalities were both visible and illegitimate to students from BME and working class backgrounds, whilst the power holders were oblivious to class and race based disadvantage.

Heeding this call, Ipek (2016) explored the dynamics of privilege in careers of senior civil servants in Britain using Acker's concept of inequality regimes with each component as a key constitute of the theoretical framing of her doctoral research. Ipek argues that although Acker's (2006a, b) work does not focus on careers per se, the components of inequality regimes are inherently linked to career processes. Furthermore, she points out that one of the key contributions of Acker's inequality regimes to her work was the ability to move beyond the choices versus circumstances duality that largely dominates career studies. The analytical power of the concept of inequality regimes lies in its ability to direct our attention to the foundational assumptions that shape career chances, choices, barriers and obstacles. In that context, Ipek (2016) finds the senior civil service in Britain a particularly interesting case because the civil service values of neutrality, impartiality, integrity and objectivity are utilized to render invisible the historically-rooted, gendered, racialized and class-based inequalities. As Ipek's doctoral study demonstrates, the concept of inequality regimes is instrumental in unpacking and debunking the assumptions that inform the idea of meritocracy, which serves to legitimize structural inequalities and privilege in organizations.

Furthermore, Ipek's (2016) research evidenced the fleeting and subtle forms of inequalities and privilege that were characterized by a paradox of having both high visibility and high legitimacy. For example, the greater representation of traditionally privileged groups in senior grades was recognized as an empirical fact in the context of meritocracy and neutrality by senior civil servants, but at the same time and somewhat contradictorily, was also considered random and non-systematic in nature, rather than a symptom of organizational or societal inequalities. Thus in this context, although inequalities were visible to research participants at times, they were justified as almost chance events or happenstance. Similarly, the participants 
in Tatli et al.'s (2017) research frequently referred to merit, choice and chance to justify unequal career outcomes, thus rendering male privilege invisible. Tatli et al (2017) state that although the numerical manifestations of gender inequality were visible to both men and women in Chinese organizations, antecedents of gender inequalities remained invisible not just to the privileged, but also often the disadvantaged members of the organization, thanks to the workings of internalized control and compliance.

Notwithstanding the recognition of the forces fostering compliance, our work also shows that groups experiencing inequalities also resist and challenge; they are not passive victims. Again drawing on Acker's inequality regimes, Bradley and Healy (2008, p.59) argue that where there is compliance, in a pluralist society, there will be resistance and highlight that trade unions are key collective agents of resistance in organizations and that their influence spreads through the different components of inequality regimes. The subjects of their research were black and minority ethnic women in unions, women who in different ways exemplified forms of resistance, whether by challenging existing practices, calling out racism, through raising grievances or appeals, by working for equality within their union, by seeking new employment opportunities where their abilities would be appreciated, by anti-racist campaigning in the community or by playing an active part in their communities (Bradley and Healy, 2008, p. 227). Their motivation was a commitment to social justice and a desire to build a better world for their communities and especially for their children. Thus, those suffering from inequality regimes were often active agents seeking to ameliorate the conditions they met.

\section{Under-researched bases of inequality and their intersections}

With the concept of equality regimes, Acker sought to capture the interweaving of gender, race, class and other axes without prioritising one over the other, seeing race, gender and class as "simultaneous processes, socially constructed, historically and geographically 
specific, and involving material, ideological and psychological elements which create and recreate unequal economic and power distributions." (Acker, 2006a, p. 39). In other words, they are mutually constituted. As these identity strands bleed into each other in complex and unpredictable patterns, individual workers experience a dramatically varied range of advantages and disadvantages (sometimes simultaneously) in the workplace.

A puzzle with which we grappled was Acker's positioning of three equality strands at the centre in her conception of intersectionality, putting race, gender and, class at the forefront whilst other structural and historical differences are pushed to the margins. Yet, Acker (2006a) does recognize that what constitutes differences that matter are historically and culturally defined and that disparities in power, autonomy, rewards and rights based on ethnicity, religion, age, physical ability and sexuality are also widely apparent bases of inequalities (ibid p.111). In this sense, she leaves the door open for other historically and culturally defined differences.

In bringing in other differences from the margins, this paper provides further insights into a number of less researched differences: sexuality, class-based inequalities, religion and cultural differences, and place of qualification and migration.

\section{Sexuality}

Acker (2006a, b) noted that sexuality, while significant in processes of inequality, is not as thoroughly embedded in organising processes as gender, race and class. However, she appreciates that heterosexuality still shapes organizing practices. Nevertheless, many of us were uncomfortable with a framework based on an apparent pecking order between equality strands. Foundational theoretical texts such as Acker (2006a, b) that are not only widely cited but also revered by scholars across disciplines shape what is visible and invisible in the literature. When we look at the literatures on equality and diversity in organizations, sexuality, and, even more so, gender identity, still continue to be under-researched and less common 
compared to race and gender (Ozturk and Tatli, 2016). Interestingly, social class, which is one of the three key strands in Acker's theory, has not proved as prevalent in inequality regime research as race and gender either, as we elaborate towards the end of this section. Nevertheless, Acker's (2006b) ex ante determination of which particular identities carry the greatest significance within organizational processes and practices is potentially a drawback, for example, if it results, although not her intention, in the injudicious negation of other strands, including for example, sexuality and religion, as key categories.

Wright (2011) argued that sexuality - and in particular dominant heterosexuality - has a central place in organizational processes and is deeply entwined with gender and class. In male-dominated occupations within the transport and construction sectors, which were the focus of her doctoral thesis and later book (Wright, 2016a), sexuality emerged as a particularly salient focus of the control and compliance component in relation to both heterosexual women and lesbians. A further component of inequality regimes is the visibility, or degree of awareness, of inequality in organizations by those in dominant positions, with lack of recognition sometimes intentional and other times not. It is also the case that dominant heterosexual groups often do not see their own heterosexual privilege, or the disadvantage faced by others, as observed earlier in relation to other privileged groups. Visibility, or lack of it, operates to marginalize non-heterosexual minorities, and Acker observed that minority sexuality is almost always invisible to the heterosexual majority: "Heterosexuality is simply assumed, not questioned" (Acker 2006b, p. 452). Awareness of context, though, was crucial to Acker, and Wright $(2013 ;$ 2016a) argued that while many organizations may have lower levels of awareness of, and experience dealing with, homophobic harassment than sexual harassment, for example, there have been significant advances in employer attitudes to LGBT employees resulting from increased legal rights and broader conceptions of the diversity agenda (Wright, 
2013; 2016a; Colgan and Rumens, 2015), not least due to the active engagement of the LGBT lobby .

\section{Class based inequalities}

Acker's conception of inequality regimes, used as an orienting device to uncover emic, and often surprising intersectionalites, allowed Tatli and Özbilgin (2012a) to go beyond appearances and dig deeper into what constitutes advantage and disadvantage in the arts and cultural sector. They argue that the sector provides a fascinating context to research intersectionality of inequalities due to the presumed inclusivity in terms of gender and sexual orientation. One of the key findings of the study was the treatment of placement students as a cheap or free labour resource by host organizations, leading to class-based exclusion from the sector. Acker (2006a, b) notes that research on equality strands such as gender and race does not automatically address class inequalities. Likewise, Tatli and Özbilgin's (2012a) study showed that middle class bias was deeply entrenched in the arts and cultural sector, and intersected with other strands of inequality in shaping career chances and choices. Acker's inequality regimes was a key work which alerted us against class-blind analysis that may lead to misinterpretation of inequalities.

A case in point is the assumptions around a universal gay male advantage or gender equality in the arts and culture sector which quickly crumbled once we recognize that categories of gender and sexuality are complicated by class bias and intersected with the historically constituted race bias. Similarly, Ipek (2016) identified class as an essential analytical category to understand the intersectional disadvantage and privilege in senior civil servant careers. Acker's sustained focus on class, at a time when many were more preoccupied with exploring the intersections of gender and race (Walby, Armstrong and Strid, 2012), also led Wright $(2016 \mathrm{a}, \mathrm{b})$ to include occupational group as a primary category for data collection 
and analysis, alongside gender and sexuality, in women's experiences of male-dominated work. This was prompted by an awareness that while sexuality is often overlooked in intersectional analysis, the intersections of class and sexuality are among the least explored (Taylor, 2005; McDermott, 2011).

Occupational group was a recurrent theme in our work (for example, Healy and Oikelome, 2011; Seierstad and Healy, 2012; Wright, 2016a; Ipek, 2016). Healy and Oikelome (2011) argued that the social processes linked to hierarchy and class position have a universality in status-oriented societies (2011, p. 137) that is further complicated by the intersection of class with gender, sexuality, religion, race and ethnicity. Healy and Oikelome's (2011) research on front-line hospital workers showed how social processes are crucial in understanding the simultaneous nature of visibility and invisibility and how power relations sustain and reproduce discrimination. The relational consequences of the simultaneity of the visibility and invisibility of black and minority staff work within and between hierarchies and also between patients and staff; moreover differential treatment may be manifest not necessarily in what people say, but in the way that things are said and the attitude to individuals that is conveyed (2011, pp. 147-148). Thus, we see again how class plays out in the 'interactions while doing work'.

\section{Religion and cultural difference}

A further under-explored intersection is that of religion, gender and class. Healy et al. (2011) used an intersectional sensibility, following Crenshaw's (1991) view that an intersectional sensibility is a central theoretical and political objective of anti-racism and feminism, in conjunction with Acker's inequality regimes to explore the paradox of how inequality regimes are sustained, despite the existence in the public sector of more sophisticated policy development and stronger legal duties than in the private sector. They set out to do this 
in the context of Caribbean, Bangladeshi and Pakistani (CBP) women (the most disadvantaged groups in the UK (EOC 2007)). In this research, in addition to the intersections of gender, ethnicity and race, it was clear that different cultural traditions and hierarchy became central parts of the inequality picture.

The article showed how white managers had different perceptions than for example Caribbean managers who had greater empathy with the experiences of CBP subordinates. Moreover, the question of religion was seen as a basis of inequality with respect to dress, access to prayer rooms, flexibility to pray and exclusion from venues with alcohol and gambling. The research identified a form of racialized/nationality undervaluation. Bangladeshi and Pakistani women in certain work contexts such as health and education, were sometime called away from their work duties to translate for a parent or patient. Pakistani and Bangladeshi women reported that a second or third language was seen as a taken-for-granted, free resource extracted according to organizational need. Healy et al. (2011) argued that racialized undervaluation may result in an intensification of an individual's workload, yet the increased workload remains unrecognized in formal and informal appraisals and reward processes. If individuals do not 'donate' their linguistic skills this may be perceived as non-compliance. Yet to comply leads to the reproduction and rationalization of gendered racialized undervaluations (Healy et al., 2011, p. 472). They also argue for recognition of the dynamic quality of Acker's work on inequality regimes and intersectionality. For example, while the components of inequality regimes are separated analytically, in reality they are mutually constitutive and in constant processes of construction, taking us far from an additive approach to intersectionality (ibid p.483).

\section{Place of qualification and migration}

On the theme of under-explored intersections, Oikelome and Healy (2013) found that a critical intersection for some occupational groups (in this case, doctors) was place of 
qualification, which of course is often interrelated with migration (Healy and Oikelome, 2011; Oikeleme and Healy, 2013). Following Acker, they aimed to identify key practices that lead to the resilience of inequality regimes for medical practitioners, particularly with respect to gender, place of qualification, and differences in the perception of inequality, morale and career aspiration of doctors. From Oikelome and Healy's quantitative analysis of British Medical Association data, it was clear that the mutually constituted gendered and racialized intersectional experiences of IMG (International Medical Graduates ${ }^{\text {ii }}$ ) women doctors sets them apart from their UK qualified counterparts and showed that they were the most disadvantaged group compared to both male IMGs and UK qualified doctors, despite the presumed protection of high human capital (Oikelome and Healy, 2013 p.1). Thus, class advantage is not a given and may be reduced by migration status.

Oikelome and Healy's study provides a timely warning to quantitative researchers on occupational studies to avoid binary analysis, e.g. men/women, migrant/non-migrant, overseas qualified/UK (or US) qualified binaries which offer only a partial picture of the reality of medical working experiences in the global North. Migration is seen as a contemporary issue, and researchers need to adopt a complex intersectional analysis to enable a comprehensive account of migrants' experiences and to the uncovering of the differences within and between groups, a task which the inequalities regime approach is well suited. Migration studies of occupational groups will benefit from investigations that not only compares migrants with nonmigrants but also considers the gender differences within the migrant group and between women migrants and non-migrants in similar occupations taking into account place of qualification and country of origin. Oikelome and Healy show that an approach informed by Acker's inequality regimes and an intersectional sensibility will serve as a reminder to researchers to be open to new forms of status distinction within stratified and segregated 
occupations, such as medicine (2013: 17), and in this case migration and place of qualification were critical variables in their intersectional analysis (ibid p.16).

\section{Where do we go from here? Acker-ian projections of future research}

For us, empirical flexibility has been vital in our application of Acker's notions of inequality regimes and intersectionality. We used inequality regimes beyond the organizational level at sectoral and occupational levels (e.g. Healy and Oikelome, 2011; Seierstad, 2011; Tatli and Özbilgin, 2012a; Tatli et al. 2017; Wright 2016a). Our studies explored intersectionality of not only gender, race and class, but also sexual orientation, gender identity, migration, place of qualification and other forms of emic categories of privilege, whose form and content is context-bound such as appearance, manners and accent (Healy and Oikelome, 2011; Ipek, 2016; Wright, 2011; Özbilgin, Beauregard, Tatli and Bell, 2011; Tatli and Özbilgin, 2012a, b). Although Acker's theory of inequality regimes has been traditionally applied in the Western context, we showed that with due sensitivity to local cultural context, inequality regimes can be employed in a way that cuts deep into gender inequalities in organizations in diverse regions of the world (e.g. Seierstad, 2011; Tatli et al., 2017; Healy and Oikelome ,2011). In this article, we have sought to make sense of a range of empirical studies that engage with Acker's work on inequality regimes and intersectionality. We recognize important limitations to our work, particularly with respect to disability and age in the portrayal of our empirical work and without doubt, Acker scholars are likely to uncover other surprising intersectionalities that become prominent in different historical, contextual and relational settings.

Acker's choice to directly implicate organization in the reproduction of inequalities is one informed by her deep scepticism of the viability of true gender equality within the capitalist organizational form. In her view, the eradication of inequality is possible only through a fundamental reconfiguration of organizational life, where responsibilities in and outside work 
are ascribed equal value, work and non-work activities are aligned in rhythm and timing, power hierarchies are crushed, and workers control the organization (Acker, 1990, pp. 154-155). Empirically affirming Acker's (1990, 2006a, b) lifelong project of questioning and problematising the commercial organization as the bulwark of inequalities, Tatli, et al.'s (2017) research on women managers in Chinese private sector organizations found that gender equality is constructed as immaterial and thus extraneous to the core aims of organizations operating in the commercial marketplace. Moreover, inequality regimes were found to be thriving in public sector organizations explicitly committed to equality values (Healy et al., 2011; Healy and Oikelome, 2011) and social democratic countries where affirmative action had been introduced (Seierstad, 2011, Seierstad and Healy, 2012).

Acker's dramatic vision is especially apposite in the neoliberal era, with the gradual trouncing of the state by market forces. Acker's radical recipe for equality contrasts starkly with that of liberal feminist scholarship on gender inequalities. For example, one of the foundational scholars in management and organization, Kanter (1977) espouses balanced representation across all job types and levels as a means of resolving the structural problem of gender inequality. The lack of doubt regarding the coexistence of equalities and capitalism is also apparent in the works of Nussbaum, a contemporary pre-eminent liberal feminist. Nussbaum (2001) conceptualizes a holistic model of capabilities for the attainment of full human freedom which could negate inequalities in social and organizational life. Yet, she too falls short of suggesting that the capitalist organization needs fundamental overhaul.

What makes Acker's position so intellectually revolutionary is her starting point which she is unafraid to carry to its organic conclusion. There is every likelihood that the neoliberal organization, as we know it, is fundamentally at odds with pursuing a genuine equality project across the strands of gender, race and class among others. For example, Acker (2006a) argues throughout her book Class questions: feminist answers that capitalism propagates itself through 
organization, which wages war against labour. Equally, we recognize the virtual universality of male domination in its classed and racialised forms in multiple societal types, and that importantly, organizations function as the catalyst of class, gender and race inequalities in society. While much of our research is targeted at organizations where it may fall on deaf ears so that the imperative of contemporary capitalism, decentralization and increasingly insecure work suggests that our research work aimed at challenging inequalities will only ever be partially effective. Despite these barriers, let our journey into the future with Acker continue to reflect the intent of Acker's theoretical insights and endeavour towards exposing, demystifying, denaturalising complex and intersectional inequalities, which mould capitalist and other organizations into enduring inequality regimes. We give the last words to Acker herself:

'Sometimes extraordinarily vocal movements suddenly and unexpectedly escalate to levels that actually produce changes that make a difference. The civil rights movement and the women's movement are two twentieth-century examples in the United States. Global corporate capital seems to be in control at the moment, but changes toward radically restructuring gendered and racialized class practices, and reversing the race to the bottom in living and working conditions, could come as more and more people confront the realities that global market capitalism has brought affluence to perhaps the top 20 per cent of the world's population, anxiety and insecurity to others who still are consuming and surviving, but deep poverty and desperation to the rest.' (Acker 2006a, p. 185).

Note: With thanks to Joan Acker from the Centre for Research in Equality and Diversity (CRED) for her insights and inspiration. 


\section{References:}

Acker, J. (1989). Doing Comparable Worth - Gender, Class and Pay Equity. Philadelphia, Temple University Press.

Acker, J. (1990). Hierarchies, Jobs and Bodies - A theory of gendered organizations. Gender \& Society, 4,2, 139-158.

Acker, J. (2006a). Class Questions: Feminist Answers. Lanham, MD: Rowman \& Littlefield.

Acker, J. (2006b). Inequality regimes gender, class, and race in organizations. Gender \& society, 20,4, 441-464.

Adkins, L. (1995). Gendered work: sexuality, family and the labour market. Buckingam, UK: Open University Press.

Anthias, F. (1998). Rethinking social divisions: some notes towards a theoretical framework. Sociological Review, 46,3, 505-535.

Bradley, H. and G. Healy (2008). Ethnicity and Gender at Work: inequalities, careers and employment relations. London and New York, Palgrave and Macmillan.

Brah, A. and A. Phoenix (2004). Ain't I a woman? Revisiting intersectionality. Journal of International Women's Studies, 5,3, 75-86.

Britton, D. M., and Logan, L. (2008). Gendered organizations: progress and prospects. Sociology Compass, 2,1, 107-121.

Burrell and Hearn (1989). The sexuality of organization. In J. Hearn, D. L. Sheppard, P. Tancred-Sheriff, \& G. Burrell (Eds.), The sexuality of organization. (pp. 1-28). London: Sage.

Cockburn C (1991). In the Way of Women: Men's Resistance to Sex Equality in Organizations. Basingstoke: Macmillan.

Colgan, F. and N. Rumens, Eds. (2015). Sexual Orientation at Work: Contemporary Issues and Perspectives. Abingdon, Oxon, Routledge.

Collins, P. H. (2000). Black Feminist Thought. New York, Routledge.

Crenshaw, K. (1991). Mapping the Margins: Intersectionality, identity politics and violence agains women of color. Stanford Law Review, 43,6, 1241-1299.

EOC (2007). Key Statistics - Moving on up? Bangladeshi, Pakistani and Black Caribbean women and work. Manchester, Equal Opportunities Commission.

Esping-Andersen, G. (2002). Why we need a new welfare state. Oxford, Oxford University Press. 
Halford, S., Savage, M., \& Witz, A. (1997). Gender, careers and organizations: current developments in banking, nursing and local government. London: Macmillan.

Hancock, A.M. (2007). Intersectionality as a Normative and Empirical Paradigm. Politics \& Gender, 3,02, 248-254.

Healy, G., Bradley, H. and Forson, C. (2011) Intersectional Sensibilities in Analysing Inequality Regimes in Public Sector Organizations. Gender, Work and Organization, 18, 467-487.

Healy and Oikelome, 2011 Diversity, Ethnicity, Migration and Work - International perspectives. Palgrave Macmillan: Basingstoke.

hooks, b. (2000). Feminist Theory: from margin to center. Cambridge, South End Press Classics.

Ipek, G. (2016). Privilege, careers and the Civil Service in Britain. PhD thesis, Queen Mary University of London.

Kanter, R. M. (1977). Men and women of the corporation. New York: Basic Books.

McCall, L. (2005). The Complexity of Intersectionality. Signs: Journal of Women in Culture and Society, 30,3, 1771-1800.

McDermott, E. (2011). Multiplex methodologies: Researching young people's well-being at the intersections of class, sexuality, gender and age. In Y. Taylor, S. Hines and M.E. Casey (eds), Theorizing Intersectionality and Sexuality. Basingstoke: Palgrave Macmillan, 235-254.

McDowell, L. (1997). Capital culture: gender at work in the city. Blackwell, Oxford.

Nussbaum, M. C. (2001). Women and human development: The capabilities approach. New York: Cambridge University Press.

Oikelome F. and Healy, G. (2013) Gender, Migration and Place of Qualification of Doctors in the UK: Perceptions of Inequality, Morale and Career Aspiration. Journal of Ethnic and Migration Studies 39(4): 557-577.

Özbilgin, M., Beauregard, T.A., Tatli, A. \& Bell, M.P. (2011) Work-Life, Diversity and Intersectionality: A Critical Review and Research Agenda. International Journal of Management Reviews, 13: 177-198.

Özturk, M. B., and Tatli, A. (2016). Gender identity inclusion in the workplace: broadening diversity management research and practice through the case of transgender employees in the UK. International Journal of Human Resource Management, 27,8, 781-802.

Seierstad, C. (2011). Exploring the Norwegian paradox of vertical sex segregation: strategies and experiences in politics, academia and company boards. PhD thesis, Queen Mary University of London. 
Seierstad, C. and Healy, G. (2012). Women's equality in the Scandinavian academy -a distant dream? Work Employment and Society, 26,2, 296-313.

Seierstad, C., Warner-Søderholm, G., Torchia, M. and Huse, M. (2017). Increasing the Number of Women on Boards: The Role of Actors and Processes. Journal of Business Ethics, 141, 2, 289-315.

Tatli, A., and Özbilgin, M. (2012a). Surprising intersectionalities of inequality and privilege: the case of the arts and cultural sector. Equality, Diversity and Inclusion: An International Journal, 31, 249-265.

Tatli, A., and Özbilgin, M. F. (2012b). An emic approach to intersectional study of diversity at work: a Bourdieuan framing. International Journal of Management Reviews, 14,2, 180200.

Tatli, A., Özturk, M. B., and Woo, H. S. (2017). Individualization and Marketization of Responsibility for Gender Equality: The Case of Female Managers in China. Human Resource Management. 56, 3, 407-430.

Taylor, Y. (2005). The Gap and How to Mind It: Intersections of Class and Sexuality (Research Note). Sociological Research Online, 10,3.

Walby, S., Armstrong, J. and Strid, S. (2012). Intersectionality: Multiple Inequalities in Social Theory. Sociology, 46, 224-240.

Wolkowitz, C. (2006). Bodies at work. London: Sage.

World Economic Forum (2017) The Global Gender Gap 2017. http://www3.weforum.org/docs/WEF_GGGR_2017.pdf (accessed November 2017) ISBN 978-1-944835-12-5.

Wright, T. (2011). Gender and sexuality in non-traditionally female work: an intersectional analysis of the experience of women in different occupational groups in the UK construction and transport industries. PhD thesis, Queen Mary, University of London.

Wright, T. (2013). Uncovering sexuality and gender: an intersectional examination of women's experience in UK construction. Construction Management and Economics, 31, 832-844.

Wright, T. (2016a). Gender and sexuality in male-dominated occupations: women workers in construction and transport. Basingstoke: Palgrave Macmillan.

Wright, T. (2016b). Women's Experience of Workplace Interactions in Male-Dominated Work: The Intersections of Gender, Sexuality and Occupational Group. Gender, Work and Organization, 23, 348-362.

Young, I. M. (1990). Justice and the Politics of Difference. Princeton, Princeton University Press.

\footnotetext{
i The Centre for Research in Equality (CRED) began in 2005 by bringing together the work of Geraldine Healy, Gill Kirton and Mustafa Özbilgin, with doctoral researchers, Cynthia Forson, Gözde Inal and Ahu Tatli, and
} 
research fellows, Franklin Oikelome and Charlene Williams, who were soon joined by Mike Noon and as doctoral researchers, Cathrine Seierstad and Tessa Wright (both with Tatli, now academic members of CRED).

${ }^{\text {ii }}$ IMG is the term used for overseas qualified doctors/physicians in the UK and USA. 